\title{
WEHLER, Hans-Ulrich, Scheidewege der deutschen Geschichte. Von der Reformation bis zur Wende
} 1517-1989

\section{Christophe Duhamelle}

\section{(2) OpenEdition}

12 Journals

Édition électronique

URL : http://journals.openedition.org/ifha/1886

DOI : $10.4000 /$ ifha. 1886

ISSN : 2198-8943

\section{Éditeur}

IFRA - Institut franco-allemand (sciences historiques et sociales)

Référence électronique

Christophe Duhamelle, «WEHLER, Hans-Ulrich, Scheidewege der deutschen Geschichte. Von der Reformation bis zur Wende 1517-1989», Revue de I'IFHA [En ligne], Date de recension, mis en ligne le 01 janvier 1995, consulté le 22 septembre 2020. URL : http://journals.openedition.org/ifha/1886 ; DOI : https://doi.org/10.4000/ifha. 1886

Ce document a été généré automatiquement le 22 septembre 2020.

(CIFHA 


\section{WEHLER, Hans-Ulrich, Scheidewege der deutschen Geschichte. Von der Reformation bis zur Wende 1517-1989}

Christophe Duhamelle 
1 Que ce soit H.-U.W. qui, dans l'introduction de ce recueil, souligne le rôle des événements, des décisions parfois acquises de justesse dans le choix entre divers possibles dont aucun ne peut prétendre au statut de nécessité - que ce soit lui qui envisage des questions comme: que se serait-il passé si le roi Guillaume de Prusse avait abdiqué en 1862 ou si Hitler n'avait pas obtenu la nationalité allemande? - constitue un bon indice des évolutions historiographiques entraînées par la "surprise " de 1989, l'influence de T. Nipperdey ou plus généralement par un Zeitgeist qui, bien au-delà de la corporation historienne, tend à ne plus subordonner l'étude des césures des processus évolutifs aux directions générales que ces derniers empruntent.

2 C'est dans cette orientation globale que réside le premier intérêt de cet ouvrage qui réunit dix-huit conférences prononcées en 1993 pour l'université radiodiffusée. L'autre intérêt est de présenter, sur la Réforme (H. Schilling) ou la Wende de 1989 (J. Kocka), le nationalisme allemand (H.-U. Wehler) ou la prise de pouvoir par Hitler (B. Weisbrod), sur la guerre des Paysans (W. Schulze) ou la révolution de 1848 (W. Siemann), l'Etat social (G.A. Ritter), la Première Guerre mondiale (G. Mai) et la Seconde (U. Herbert) ou la guerre de Trente Ans (J. Burkhardt), la confessionnalisation (R. v. Thadden), la « révolution des médias » aux XVIe-XVIIe s. (B. Sösemann) ou la révolution industrielle (W. Abelshauser), l'avènement d'une société de classes (H. Reif), les rapports entre nazisme et modernité (J. Radkau) ou la reconstruction d'après-guerre (F.J. Brüggemeier), la fondation du IIe Reich (D. Langewiesche) ou celle de la R.F.A. et de la R.D.A. (D. Staritz), des textes synthétiques qui offrent sur un événement ou une évolution, ainsi que sur ses différentes interprétations, la réflexion condensée des meilleurs spécialistes. Une lecture agréable et stimulante. 